\title{
Increasing appropriate complementary feeding in rural Uttar Pradesh: Implications for behavior change communication
}

Population Council

Follow this and additional works at: https://knowledgecommons.popcouncil.org/departments_sbsr-rh

Part of the Demography, Population, and Ecology Commons, Family, Life Course, and Society Commons, International Public Health Commons, Maternal and Child Health Commons, and the Public Health Education and Promotion Commons How does access to this work benefit you? Let us know!

\section{Recommended Citation}

Population Council. 2010. "Increasing appropriate complementary feeding in rural Uttar Pradesh: Implications for behavior change communication," Shaping Demand and Practices to Improve Family Health Outcomes in Northern India Policy Brief no. 6. New Delhi: Population Council. 


\section{Increasing appropriate complementary feeding in rural Uttar Pradesh: Implications for behavior change communication}

\section{Background}

The Government of India has recommended that complementary feeding of infants should be started at the age of 6 months. The three recommended infant and young child feeding practices for children aged 6-23 months include: continue breastfeeding; feed semi-solid/solid food according to the age of the child; and feed a variety of foods such as cereals, fruits, vegetables and milk ${ }^{1}$. It is recommended that children aged 6-8 months should be given complementary food twice a day while children aged 9-23 months should be fed three times a day. The amount of food given should be equivalent to $200 \mathrm{Kcal}$ per day for children aged 6-8 months, $300 \mathrm{Kcal}$ per day for children aged 9-11 months and 550 Kcal per day for children aged 12-23 months ${ }^{2}$.

NFHS-3 data show that only 22 percent of children aged 6-23 months were given appropriate complementary food in rural UP ${ }^{3}$. DLHS-3 data indicate that, only 25 percent of children aged 6-23 months had started complementary food at the recommended age of 6 months.

In October 2009, the Population Council conducted a formative study in rural UP to determine current complementary feeding practices among children aged 6-23 months; understand the facilitating factors and barriers in adopting appropriate complementary feeding practices; and identify programmatic and behavior change communication (BCC) initiatives that could promote the adoption of appropriate complementary feeding practices. The project was funded by the Bill and Melinda Gates Foundation.

\section{Methodology}

The formative study was conducted in two phases. First, a survey was conducted covering 4,754 households, 4,472 currently married women aged 15-34 years who had delivered a child in the last three years, 2,274 husbands, 2,372 mothers-in-law, 289 ASHAs, 284 AWWs, 161 ANMs, 316 local private practitioners, 251 panchayat members (including Village Health and Sanitation Committee members) and staff at 144 government health facilities (PHCs and CHCs) from 225 villages in 12 districts spread across the Western, Central and Eastern regions of UP. In the second phase, 308 in-depth interviews were conducted with family-level stakeholders (women, husbands and mothers-in-law), health care providers (ASHAs, AWWs, private practitioners and dais) and panchayat members to complement the information gathered in the quantitative survey. The qualitative study was conducted in 24 villages-eight villages each from three districts, one district from each of the three regions. As in NFHS-3, in the household survey conducted by the Population Council, information was collected on the frequency and type of food fed to a child; the quantity of complementary food given to a child was explored only in the qualitative study.

\section{Key findings}

Status: The formative study shows that among children aged 6-23 months $(\mathrm{N}=2,386)$, only 24 percent of were given appropriate complementary food, an increase of just 2 percent points since 2005-06 (NFHS-3) ${ }^{4}$. The appropriate complementary feeding-that is,

\footnotetext{
${ }^{1}$ GOI. 2004. National Guideline on Infant and Young Child Feeding <http://wcd.nic.in/national_guidelines.html> ${ }_{2}^{2}$ AED. n.d. Guideline for Appropriate Complementary Feeding of Breastfed Children 6-24 Months of Age. Facts for Feeding. LINKAGES Project < http://www.linkagesproject.org/publications/>

${ }^{3}$ Data from NFHS-3 and DLHS-3 presented in this policy brief are based on an analysis, conducted by the Population Council, of currently married women aged 15-34 in rural UP who had given birth in the three years preceding the survey.

${ }^{4}$ K. Aruldas, M.E. Khan and A. Hazra. 2010. "Increasing Complementary Feeding in Rural Uttar Pradesh: Implications for Behavior Change Communication," in M.E. Khan, Gary Darmstadt, T. Usha Kiran and D. Ganju, eds. Shaping Demand and Practices to
} Improve Family Health Outcomes: A Formative Study in Rural Uttar Pradesh. New Delhi: Population Council (forthcoming). 


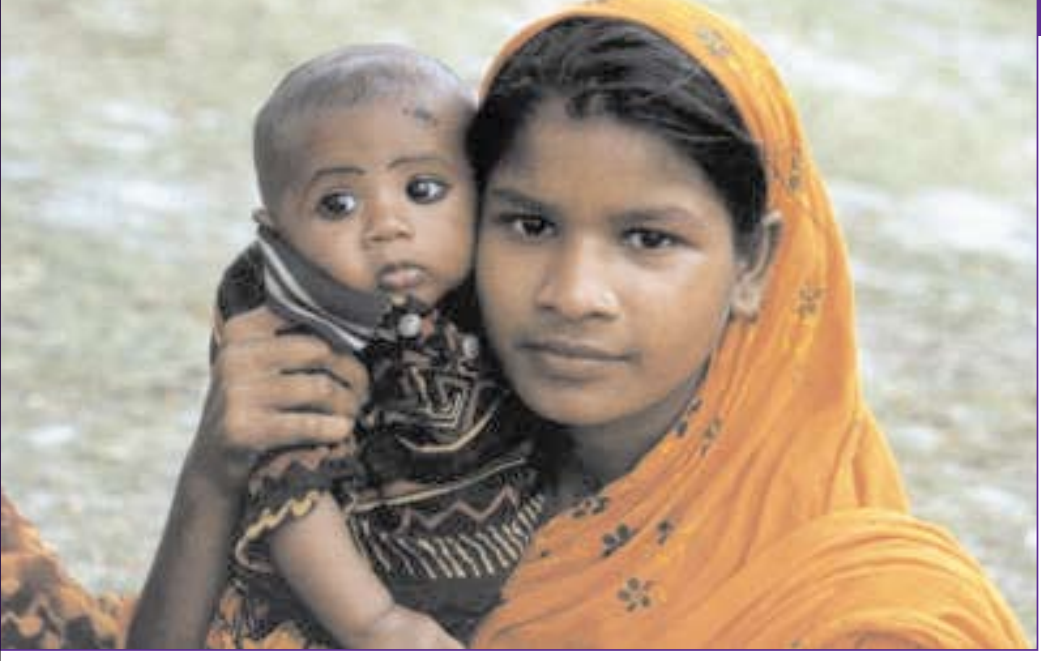

type of food and frequency of feeds given-was low across all age groups (Figure 1).

\section{Figure 1: Status of appropriate complementary feeding}

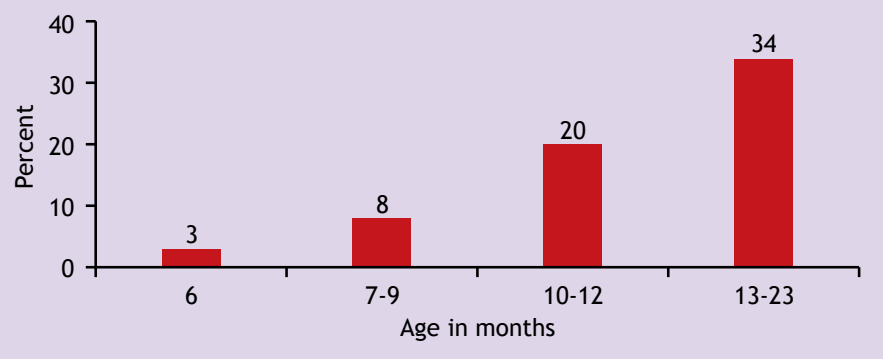

By and large, the introduction of complementary feeding was delayed. Only 13 percent of children were started on complementary food at the correct age of 6 months. While in most cases (46 percent) complementary feeding was initiated between 7-9 months of age, 17 percent were started on complementary feeding much later, after the age of 10 months (Table 1). As one woman said, "From the 8th month I started giving my child roti, rice and biscuit."

Table 1: Age of initiation of complimentary feeding (percent)

\begin{tabular}{|l|c|c|c|c|c|}
\multicolumn{7}{|c|}{ Age in months } \\
\hline Less than 3 & $4-5$ & 6 & $7-9$ & 10 or more & Not yet started \\
\hline 4 & 8 & 13 & 46 & 17 & 11 \\
\hline
\end{tabular}

Findings also show that 11 percent of children, mainly in the age group 6-8 months, had not been given any complementary food. The practice of initiating complementary feeding at 6 months of age was relatively higher in the Eastern region (18 percent) as compared to the Western (12 percent) and Central regions (10 percent) (ANOVA test, $\mathrm{p}<0.001$ ).

With regard to the number of times children aged 6-23 months were fed, findings show that 63 percent were given the minimum recommended number of feeds in a day. An analysis of the types of food fed to children however, reveals that only 30 percent were fed at least three types of food as recommended. In most cases, the food given was cereal based (85 percent), followed by fruits and vegetables (45 percent) and pulses (23 percent) (Figure 2).

The qualitative study shows that women and family members did not feed a measured quantity of food to their
Figure 2: Feeding practices by food groups

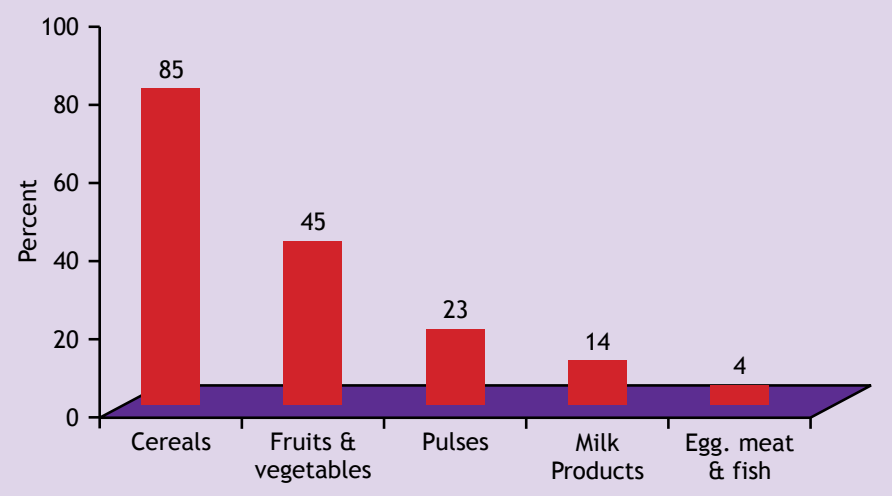

Note: Data refers to foods given 24 hours preceding the interview

children; instead, children were fed a few spoonfuls while they were eating or were given a piece of roti or biscuit to hold and left to eat by themselves.

\section{Barriers}

Lack of knowledge among women and elders: Many women (56 percent) started giving supplementary food like animal milk before 6 months of age because they felt that their breast milk was not sufficient for the child. Giving supplementary food like animal milk leads women and family members to delay initiating complementary feeding. As a mother-in-law said, "Along with mother's milk, the child is fed buffalo milk mixed with boiled water. Buffalo milk was started before 6 months of age. When the child grows up, he will start eating from his mother's plate."

Lack of knowledge and misperceptions among elderly women, like mothers-in-law, who generally influence and guide child feeding practices in the family, are often barriers to initiating complementary feeding at the correct age. Only 20 percent of mothers-in-law correctly reported that complementary feeding should be initiated at the age of 6 months; 67 percent reported that complementary food should be started after the child is 7 months old. One mother-in-law said, "Children aged 6-7 months should be given biscuit, daal ka paani... If mother's milk is sufficient then only breast milk should be given till one year; after that the child should be given around 1-2 spoonfuls of milk, malai, rice, chapatti mashed in daal twice a day ...."

Among women who did not give the recommended number of feeds ( $\mathrm{N}=609)$, most (83 percent) believed that the child cannot eat much, the child would have difficulty in eating more or what they were feeding was adequate (Table 2). Few (11 percent) reported that it was sufficient as the child was also breastfeeding, and 6 percent reported they were not aware how many times to feed the child.

In some cases, the feeding process is discontinued because the child gets easily getting distracted when eating. Apart from lack of knowledge, feeding children proactively requires time, which often women are unable to give because of the pressure of house work. 
Table 2: Reasons for not feeding recommended number of times

Reasons

Percent

Child can eat only so much

66

Child has difficulty eating more

Thought it was sufficient

Not aware how many times to feed

Child is breastfeeding, so perceived adequate

Cannot afford more

Others

Total

Note: Percentages do not add to 100 due to multiple responses.

Most women (72 percent) had not received information or advice on complementary feeding. Although 17 percent had been advised by their mother-in-law on complementary feeding, this did not necessarily translate into appropriate complementary feeding practices as mothers-in-law themselves did not have correct knowledge about child feeding. Only 9 percent of women reported receiving advice from health care providers on complementary feeding. These findings indicate the need to build awareness on complementary feeding practices in the family and community.

Lack of knowledge among frontline health workers: About 80 percent of frontline health workers (ASHAs, AWWs and ANMs) have correct knowledge regarding the type of complementary food to be given to a child. However, only 11-25 percent were correctly aware of the recommended frequency of feeds. The qualitative study shows that their knowledge on the quantity of food to be fed to children is low. An AWW said, "...in what quantities and when a child should be fed, I don't have any specific knowledge about it. On my own I advise that a child should be given daal ka paani, daliya, khichdi and older children should be given rice, vegetables in small- small quantities..." Another AWW said, "...I do not advise exactly how much to feed. I just say what could be fed to the child. I tell this to very few women because women do not have much time; they go to the field, cook food and do other work..." It appears that frontline health workers are not aware of the critical link between complementary feeding and child malnutrition and it consequences.

Lack of appropriate communication /counseling aids: Most AWWs and ASHAs (58 percent and 72 percent, respectively) reported they do not have any communication /counseling aids on complementary feeding. The qualitative study shows that even when provided communication /counseling materials, health workers often did not use them. They either verbally explained about complementary feeding or occasionally used a cup or a bowl from the woman's house to explain the quantity of the food to be fed. An AWW reported, “...I take a katori [small bowl] from the woman's house and show them how much to feed. If the katori is small I tell them to give double, and if it is big I tell them to give half. I have not got any training, I just tell them...." Another ASHA said, “...I was not provided any training in counseling and communication or how to use communication aids. No communication aids were provided... we got two books [modules]...."
Missed opportunity: Findings show that 73 percent of village-level private practitioners treat children aged 1-12 months; however, awareness of complementary feeding practices was limited. Only 36 percent were aware of the correct age for initiating complementary feeding; 39 percent correctly reported that at least 1 cup of food should be given each time to a child aged 6-8 months; and 10 percent correctly reported that a child should be fed twice a day, and should be fed vegetables. There is a missed opportunity for private practitioners to counsel and motivate families to adopt complementary feeding. Efforts are needed to build awareness among private practitioners about correct complementary feeding practices.

\section{Facilitating factors}

Background characteristics: The study shows that background characteristics of women such as high standard of living, education and exposure to the media are significant predictors for appropriate complementary feeding. The practice of appropriate complementary feeding was about one and a half times higher among women with a secondary or higher education as compared to women with no education (OR 1.42, p < 0.05), and about 25 percent higher among women exposed to any media as compared to those with no media exposure (OR 1.28, p<0.05).

ANC check-ups: The practice of appropriate complementary feeding was significantly higher among women who received three or more ANC check-ups as compared to those

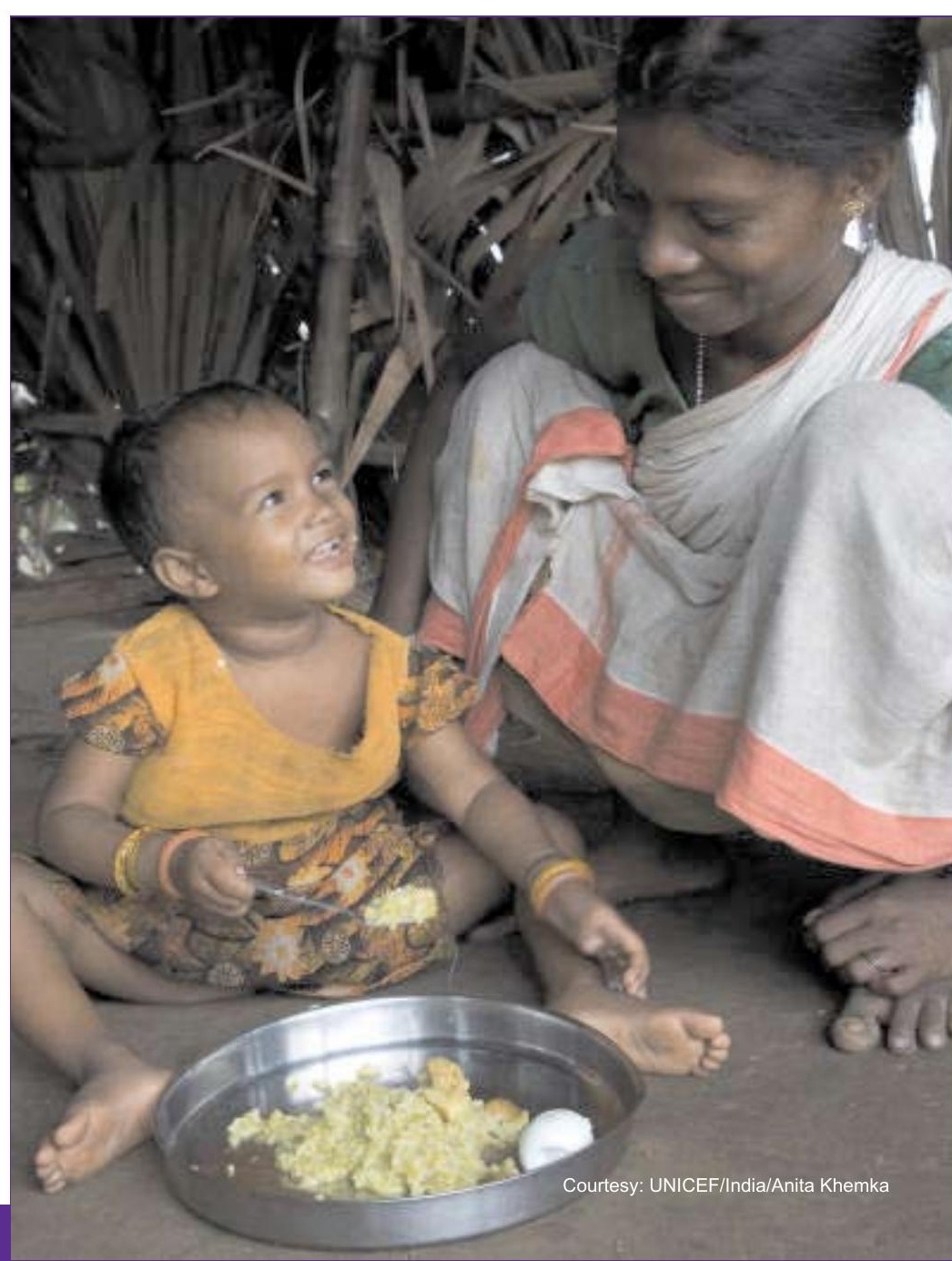


who did not receive any ANC (OR 1.12, $\mathrm{p}<0.05)$. Increasing the practice of appropriate complementary feeding would be a challenge given the finding that other program factors such as receiving advice on complementary feeding, the presence of selfhelp groups and mahila mandals, or the availability of a government facility within the village, did not have a significant effect on the uptake of the behavior.

\section{Implications for the BCC strategy}

Audience segmentation: The study shows that women and their family members, including the child's older siblings, look after the child and feed her/him small quantities of whatever they are eating. Although the child gets some food, the recommended practices of complementary feeding are not being adopted. While the entire family is involved in the process of child feeding, none of the family members are aware of the recommended quantity of food and the frequency of feeds required for the optimum growth of the child. The challenge for the BCC strategy therefore would be to reach all members of the family with the correct information on complementary feeding. Messages should also project women, mothers-in-law, and husbands as the key persons responsible for the normal growth of the child and for monitoring what the child is fed.

Build awareness among women and family members: Given the finding that knowledge of complementary feeding is limited at the family level, key messages should include information on the quantity, frequency and type of food to be fed to a child. Messages should also focus on the importance of giving adequate time to feeding the child the recommended quantity of food; and that feeding the recommended quantity of food is important for physical and mental growth of the child.

Alignment of messages: The study shows that both exposure to media and IPC (during ANC checkups) have an impact on complementary feeding. Therefore, aligning and reinforcing messages at different points of contact through BCC activities would be critical to the uptake of the desired behavior.

Building the image of frontline health workers: Although women and families consider frontline health workers to be an important source of information on healthrelated issues, they do not consider child feeding practices to be a health issue or seek information from frontline health workers on this practice. BCC strategies should build the image of frontline health workers as a reliable source of information on child feeding practices; however, frontline health workers need to be reoriented and supplied with counseling aids to effectively promote the desired practice. Home visits by frontline health workers to counsel families on complementary feeding when the child is 5 months old, just before complementary feeding should be initiated, and when the child is 8 and 11 months old to reinforce messages on the recommended quantity of food and frequency of feeds, would be helpful. These contacts could also be utilized to provide integrated messages on specific issues like family planning and measles vaccination.

Suggested citation: Population Council. 2010. Increasing complementary feeding in rural Uttar Pradesh: Implications for behavior change communication, Policy Brief No. 6. New Delhi: Population Council.

For additional information, contact: Population Council, Zone 5A, India Habitat Centre, Lodi Road, New Delhi 110003, or email info-india@popcouncil.org

\section{(2) Population Council}

Research that makes a difference

\section{Abt}

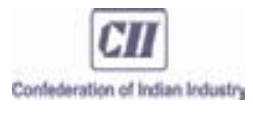

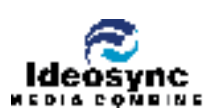
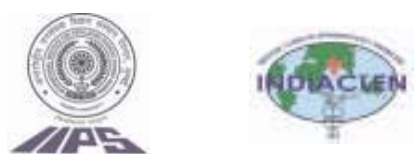

The opinions expressed in this publication do not necessarily reflect the views of the funding agencies.

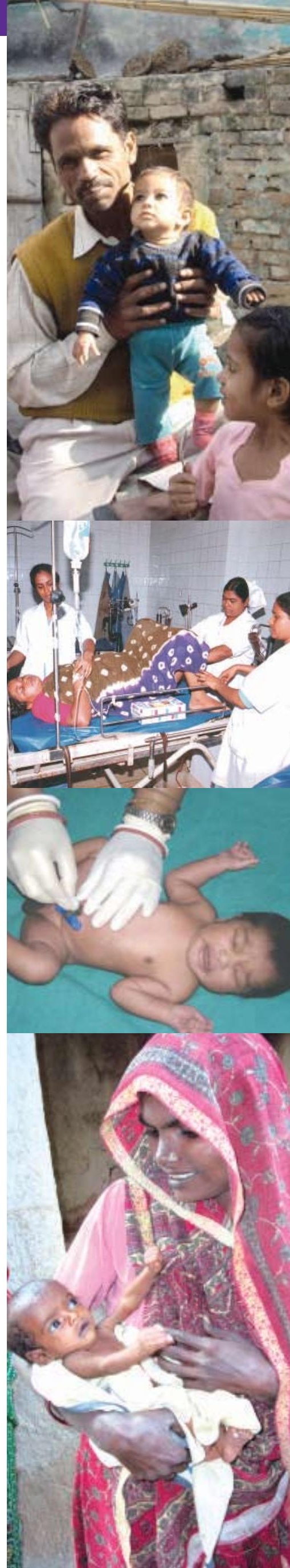

